\title{
The Matrimonial Division of the Supreme Court of Jamaica: An In-depth Look at its Work Flow Process
}

\author{
Horatio Morgan \\ Research Analyst, Supreme Court of Jamaica
}

\begin{abstract}
Upon request from Jamaica's Civil Society, the Matrimonial Division of the Supreme Court of Jamaica was highlighted as an area that needed interventions to improve its business processes cycle. This is the highest Divorce Court on the island and the numbers of application were drastically increasing resulting in a noticeable backlog. This prompted the need for a business process workflow study; focusing on the business process cycle to identify problem areas, document work flow process, identify required statistics for international partnerships, track approximate case completion rates and make recommendations for improved output. It was found that based on available resources the process was adequate considering the limited resources available. In-addition, there was a lack of available data to assist with the future developments plans of the division; and a pilot project was needed to clear up the back log.
\end{abstract}

Keywords: Workflow Process, Efficiency, Resources

I. Introduction To The Matrimonial Division OF The SUPREME COURT Of JAMAiCa Upon request from Jamaica's Civil Society, the Matrimonial Division of the Supreme Court of Jamaica was highlighted as an area that needed interventions to improve its business processes cycle. This is the highest Divorce Court on the island and the numbers of application were drastically increasing resulting in a noticeable backlog. This prompted the need for a business process workflow study; focusing on the business process cycle to identify problem areas, document work flow process, identify required statistics for international partnerships, track approximate case completion rates and make recommendations for improved output. This internal research was very important because it gathered primary data and information for the on -going Vital Statistics Project that was headed by the Planning Institute of Jamaica. In-addition this was the first work of its kind to be carried out on this division of the Supreme Court of Jamaica. Therefore, it was an exploratory look at its processes

\section{Description Of The Work Flow Proces Of The Matrimonial Division Of The Supreme Court Of Jamaica}

\section{Main Process 1}

a) Matter is commenced by a Petition/Notice of Application for Court Order/Petition of Nullity, along with an Acknowledgement of Service (Affidavit accompanying Petition if Children are involved in the Marriage).

b) The file is written up and recorded; specific demographic data is entered into JEMS.

c) The Deputy Registrar checks and signs documents. If mistakes are found in the document or issues arise a requisition is sent out to the Attorney-at-Law.

d) The file is logged to the Court Assistant who updates JEMS and place signed documents into the file kept at the window.

e) Signed Petition/Notice of Application/ Petition of Nullity collected at the window by Attorney-at-Law or authorized individual.

\section{Main Process 2}

f) Decree Nisi is filed at the window.

g) JEMS is updated to show the documents filed at the window.

h) The file is logged to the Deputy Registrar to check the Decree Nisi. If mistakes are found in the document or issues arise a requisition is sent out to the Attorney-at-Law.

i) The file is logged to a Judge to make order on Decree Nisi.

i) JEMS is Updated and the Decree Nisi placed in the file at the window

ii) Matter sent to Trial or for Court Orders in main court system outside of the Matrimonial Section.

j) The file is logged back to a Senior Court Assistant to either issue a requisition or place signed Decree Nisi in the file at the window.

k) Signed Decree Nisi or requisition collected at the window by Attorney-at-Law or authorized individual. 


\section{Main Process 3}

There is a statutory six (6) week waiting period before the Decree Absolute can be filed (Matrimonial Causes Act 1989).

1) Decree Absolute is filed at the window.

m) JEMS is updated to show the documents filed at the window.

n) Senior Court Assistant checks file and sets court date.

If mistakes are found in the document or issues arise, a requisition is sent out to the Attorney-at-Law.

o) The Judge makes the order on the Decree Absolute.

p) JEMS is updated and Decree Absolute placed in the file at the window.

q) Decree Absolute is collected at the window

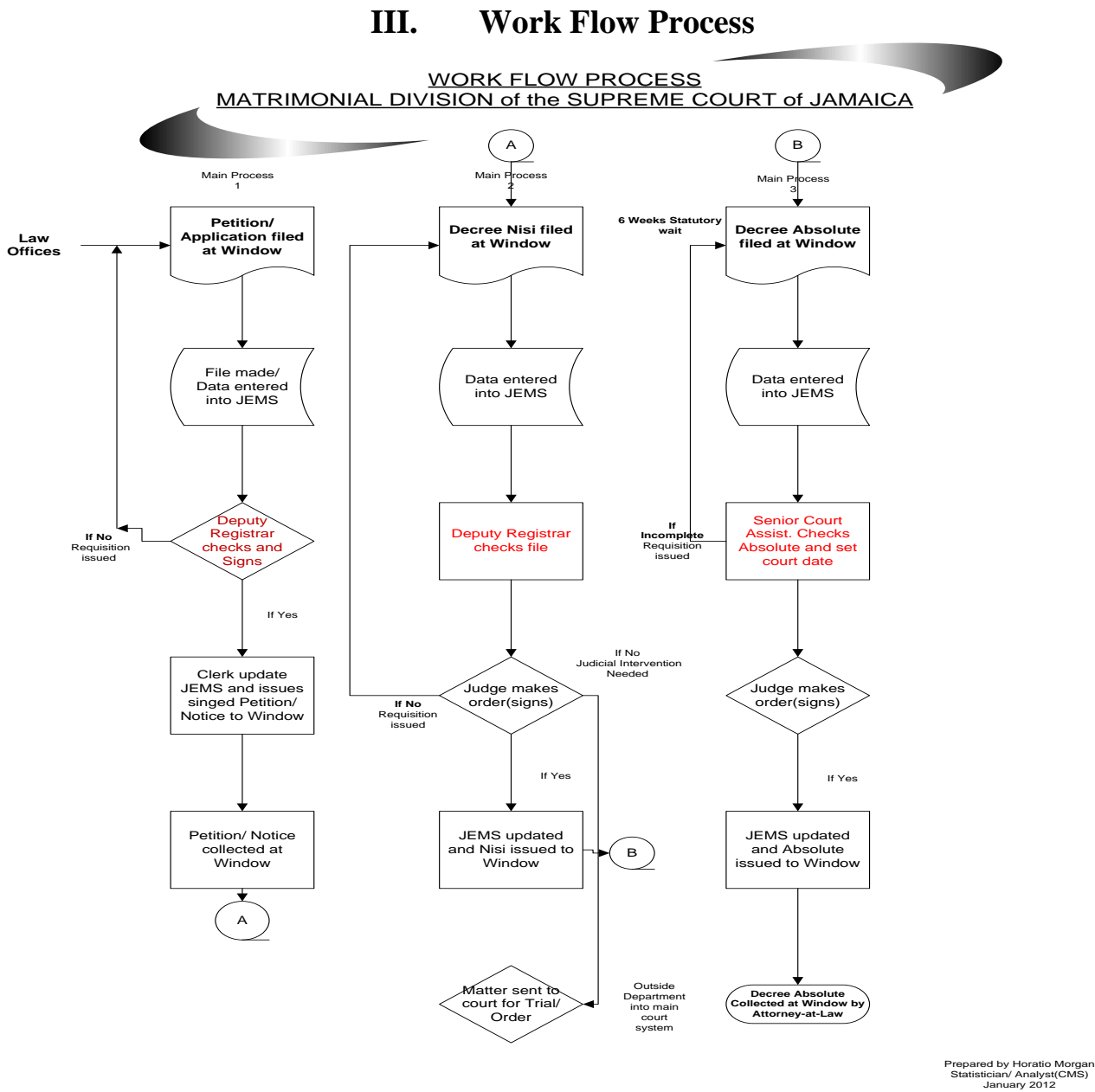

\section{Data Requirement By Different Stakeholders}

Data entered Into the Judicial Enforcement Management System (JEMS)

- Court dates

- All filed documents

- Name of parties

- Date of Marriage

- Place of Marriage

- Attorneys-at-Law involved in matter

- Date of Birth of Children

- Location/ Address of home

Data Collected By the Statistical Institute Of Jamaica

- Date of marriage

- Occupation of husband at time of marriage

- Age of husband at marriage 
- Marital status of wife marriage

- Occupation of wife at marriage

- Age of wife at marriage

- Party being sued

- Number of children at divorce

- Age of children at divorce under age 18 years

- Age of children at divorce 18 years and over

- Occupation of husband at divorce

\section{Monthly Data Sent to the Ministry Of Justice}

- Total number of Decree Nisi matters listed

- Total number of Decree Absolute matters listed

- Total number of Matrimonial Cases listed

- Total number of new cases listed

- Total number of cases carried forward

The list above is part of a major listing of data requested of the Supreme Court on a monthly basis.

\section{Break Down Of Time Period For Completion Of Divorce}

This is an example of a straight forward divorce without challenges from either party and all documents are filed correctly (no requisitions).Excluding Court Orders or Trials

1) Documents filed - 5 working days to ensure correctness of documents.

2) Wait for Deputy Registrar's signature - 2 weeks

3) Service of Documents on Respondents - anywhere from 14-56 days

4) File to get to judge at first stage -2 weeks

5) Time period for the Judge to sign file -1 week

6) Mandatory 6 week waiting period

7) Judge signs Decree Absolute - 2 weeks upward

The estimated time to complete a divorce

a) Under ideal conditions presently is 5 to 6 months.

b) With $1-3$ requisitions arising 7 to 11 months.

c) With 4 or more requisitions arising 1 year or more.

The above time periods are dependent on the response time of the Attorney-at-Law who is involved with the matter.

\section{Identified Delays In The Matrimonial Division}

a) From filling of documents to entry of data into JEMS.

b) There is not enough staff members present within the court system to adequately enter all documents promptly into JEMS or staff members are otherwise occupied multi-tasking doing other task such as checking of file working windows or attending court/chambers.

Recommendation - Hire additional staff members based on needs of the department.

c) Checking of files within the Deputy Registrar's office.

d) The Deputy Registrar thoroughly re-checks all file

Recommendation - Empower and train staff members to check file, leaving Deputy Registrar to check only relevant details within the file.

e) The large number of requisitions issued.

f) Attorneys-at-Law are not accurately preparing documents, leading to court having to duplicate the process by re-checking documents.

Recommendation - Institute an education campaign or holding workshops highlighting the main problems observed by the court when dealing with divorce documents or Prepare a document highlighting the main problems faced when dealing with divorce documents and place that document on www.supremecout.gov.jm as a public document for the public's information.

g) Absence of Judges to deal with matter promptly.

h) The Judges assign to the Supreme Court of Jamaica are limited in number and move through different parishes.

Recommendation - Increase the number of sitting Judges within the Supreme Court of Jamaica.

i) Lack of adequate notice of intention from the Attorney-at-Law to the Supreme Court. 
j) All matters go to the window and through the process until an answer is given by the respondents Attorney-at-Law; where the file is either sent to mediation or court.

Recommendation - That from the initial filing of the documents the Attorney-at-Law for the complainant notify the Court Administrator about the contentiousness of the matter and that it be dealt with promptly by the Court Administrator (setting of court date).

\section{Disposal Rate Of Files}

The conditions listed below are hypothetical and can only be applied under ideal conditions (minimum interruptions during the work day).

- $\quad$ Petitions -30 files per hour $=240$ files per day

- Decree Nisi - 1 file 5-10 minutes = 6-10 files per hour

Presently only $25 \%$ of the time is used directly to sign and check files.

\section{Major Findings And Recommendations}

1. It was found that the work flow process was presently adequate, considering the limited resources available. However, for future requirements and a faster processing time for divorces the work flow process needs to be improved to move the department closer to standards in other jurisdictions; for example in the United States of America divorces are completed in a matter of days.

Therefore, it is recommended that the work flow process be reviewed and consultations made with stakeholders to ascertain the improvements that could be made to increase efficiency within the division. This could result in the development of a modern Matrimonial Division, which would redown to the benefit of the Jamaican citizenry.

2. Based on observation, it was gleaned that accurate and up-to-date figures regarding files were not readily available. These figures could easily influence the decision making process when formulating policies for the division's development.

Therefore, it is recommended that an audit be undertaken to ascertain the exact number of files within the division and where these files are delayed within the work flow process. This should be pursued with a view to implement policies which would increase the effectiveness of the workflow process.

3. From consultations and observation, it was seen that a large number of files were not being dealt with on a timely basis and it is recommended that a project be instituted to deal with this situation.

This project should be pursued by the temporary hiring an Attorney-at-Law and support staff to work from the oldest file to the newest file without the responsibility of answering request from outside the department.

\section{Benefits Of Recommendations To The Development Of The Matrimonial Division Of The Supreme Court Of Jamaica}

a) Faster processing of divorce cases in the Matrimonial Division

b) Improved morale of the staff members leading to the development of a culture of trust and excellence.

c) Improved confidence in the Jamaican Justice System

\section{Conclusion}

In-light of the on-going reform of the Jamaican Justice System, this project is very crucial because it highlighted major challenges and benefits to the Jamaican citizenry if the recommendations are implemented and also created opportunities for further research into the area. In-addition the major findings of improving the workflow process to the creation of an accurate up to date informational management system could be included into the larger reform framework and would also result in more resources going directly into the plan for the division's improvement.

\section{REFERENCES}

